\title{
A FAMILY WITH FUNNEL CHEST IN THREE GENERATIONS
}

\author{
Yasuo SUGIURA \\ The Department of Orthopaedic Surgery, Nagoya University \\ School of Medicine, 65 Tsuruma-cho, Showa-ku, \\ Nagoya 466, Japan
}

\begin{abstract}
Summary A pedigree for funnel chest deformity is reported. In this family, 4 individuals through 3 generations are affected, showing autosomal dominant inheritance.
\end{abstract}

\section{INTRODUCTION}

Funnel chest is occasionally encountered finding in clinical practice. The author et al. have seen 8 children $(0.13 \%)$ with funnel chest of varing degrees among 6,295 healthy primary school children aged 6 to 12 years (1962). All those with funnel chest were healthy except for the deformity, which were confirmed to be sporadic in occurrence by family studies.

The purpose of this paper is to present a brief report of a family with funnel chest which apparently has been transmitted by autosomal dominant inheritance.

\section{CASE REPORT}

Proband: A 5 year-old boy (III-6).

His past history was uneventful. Clinical examination revealed a well nourished boy with normal stature of $106.5 \mathrm{~cm}$ (standard value of a normal Japanese boy at his age is $107.1 \mathrm{~cm}$ ). A very marked funnel chest in the shape of trough was observed in the mid-sternal region, measuring about $18 \mathrm{~cm}$ vertically, $10 \mathrm{~cm}$ horizontally, and $5 \mathrm{~cm}$ in depth. The upper margin extended to the level of the $3 \mathrm{rd}$ costal cartilage and the lower to the 7 th costal cartilage (Fig. 1). Cardiovascular and respiratory functions were normal. There was no other deformity, nor was the Marfanoid asthenic body type observed. Luxation of the eye lens was not seen and his visual acuity was normal.

His younger brother (III-7) (Fig. 2), his mother (II-3) (Fig. 3) and his maternal grandfather (I-1) also showed similar marked funnel chest deformity; none of them exhibited the Marfanoid asthenic body type. The family pedigree is shown in Fig. 4. 


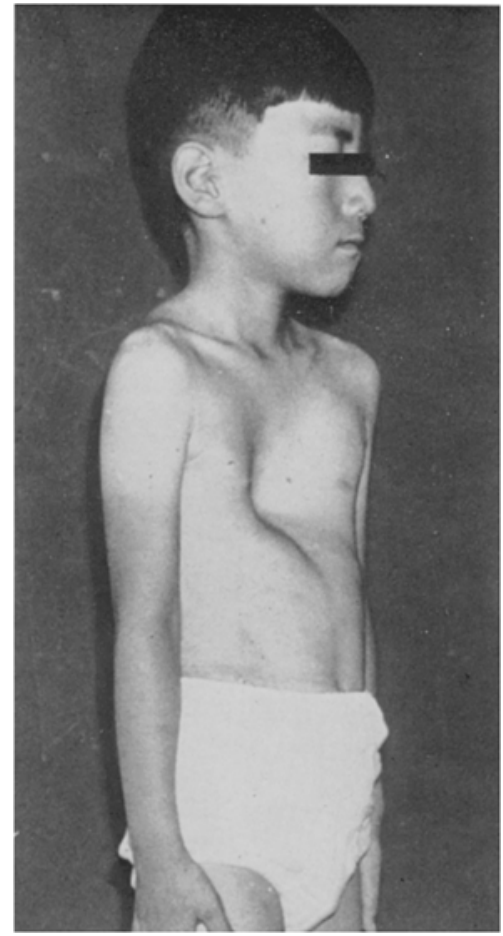

Fig. 1. External appearance of chest deformity showing marked funnel chest in the proband (III-6).

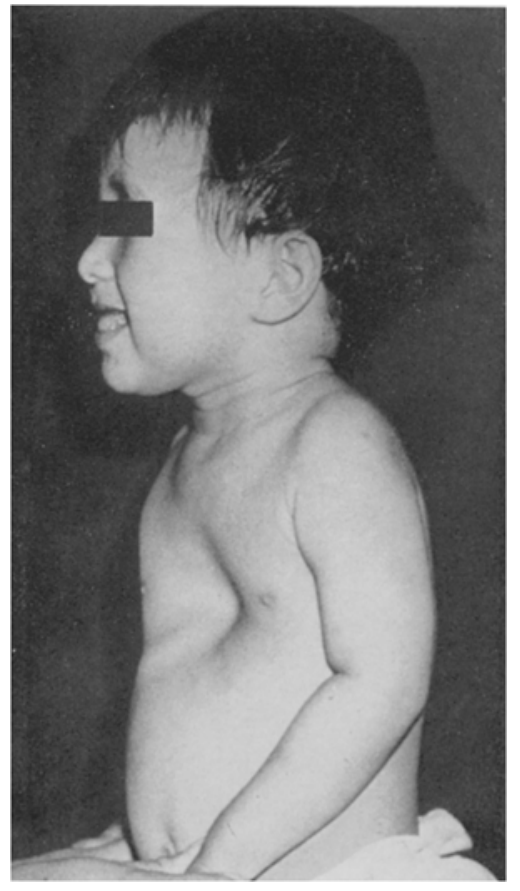

Fig. 2. External appearance of chest deformity in his younger brother (III-7).

\section{DISCUSSION}

According to Sainsbury (1947), funnel chest was first described by Eggel in 1870 . Stoddard (1939) reported funnel chest through 4 generations, and Peiper (1922), and Snyder and Curtis (1934), through 3 generations, suggesting that it can appear as a dominant character. Sainsbury (1947) descrived a family with funnel chest, in which 6 persons through 4 generations were affected by the deformation, indicating transmission as an autosomal dominant character.

The investigation of the family history for the condition is usually very difficult for the following reasons:

1) Funnel chest is seldom known to outsiders of the immediate family circle, since the deformity is normally hidden by clothing.

2) Usually the deformity causes no symptom and consequently it also tends to remain undescribed in clinical records.

3) It occurs in varying degree of severity. Several mild but definite cases have been noted in which the defect was completely missed even by the parents (Sainsbury 1947). 


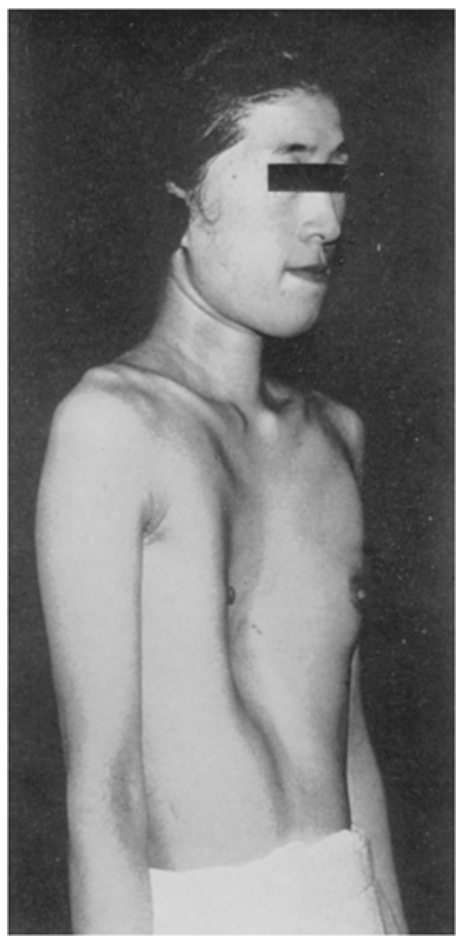

Fig. 3. External appearance of chest defornity in his mother (II-3).

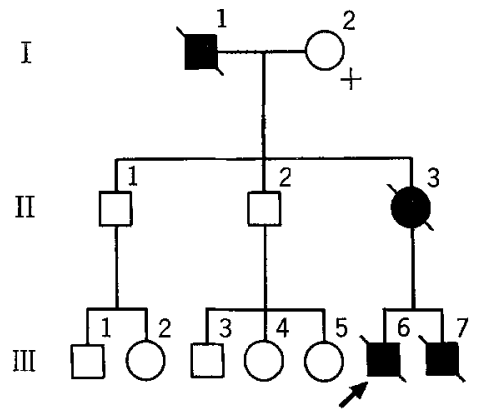

Fig. 4. Pedigree of the family.

Some of the cases of hereditary funnel chest showed only a slight depression at the lower part of the sternal body (Stoddard 1939, Sainsbury 1947). In the present case, however, a very marked depression was observed including the entire sternum, similar to that of Snyder and Curtis' case (1934). In this family, 4 individuals through 3 generations were affected, indicating autosomal dominant inheritance, as reported by other authors.

\section{REFERENCES}

Peiper, A. 1922. Über die Erblichkeit der Trichterbrust. Klin. Wschr. 1: 1647. Sainsbury, H.S.K. 1947. Congenital funnel chest. Lancet 253: 615-616. Snyder, L.H. and Curtis, G.H. 1934. An inherited "hollow chest." J. Hered. 25: 445-447. Sugiura, Y., Tajima, Y., Sugiura, I., Muramoto, K. and Wu, W. 1962. Abnormalities of musculoskeletal system observed in Shizuoka school children (Jap.). Jap. J. Human Genet. 7: 10-19. Stoddard, S.E. 1939. The inheritance of "hollow chest" "cobbler's chest" due to heredity-not an occupational deformity. J. Hered. 30: 139-141. 